\title{
Pengaruh Ketebalan Media Budidaya Cacing Sutra (Tubifex sp.) menggunakan Lumpur Limbah Budidaya Lele
}

\section{The Effect of Thickness of Medium for Silkworm (Tubifex sp.) Culture using Waste Sludge of Catfish Cultivation}

\author{
Dindin Suryadin, Senny Helmiati*, Rustadi Rustadi \\ Department of Fisheries, Faculty of Agriculture, Universitas Gadjah Mada \\ Jl. Flora Gedung A4 Bulaksumur, Yogyakarta 55281 \\ *Author for correspondence, e-mail : senny@ugm.ac.id
}

\begin{abstract}
Abstrak
Penelitian ini bertujuan untuk mengetahui pengaruh limbah budidaya lele sebagai media budidaya cacing sutera dan mendapatkan ketebalan media yang menghasilkan biomassa cacing sutera tertinggi. Penelitian dilakukan menggunakan sistem wadah bertingkat dengan aliran air secara resirkulasi. Wadah budidaya yang digunakan berukuran 40×30×20 cm $\mathrm{cm}^{3}$. Penelitian dilakukan secara eksperimen dengan rancangan penelitian berupa Rancangan Acak Kelompok Lengkap dengan empat perlakuan dan masing-masing tiga ulangan, yaitu P1 (ketebalan media $2 \mathrm{~cm}$ ); P2 (ketebalan media $4 \mathrm{~cm}$ ); P3 (ketebalan media $8 \mathrm{~cm}$ ); P4 (ketebalan media 12 $\mathrm{cm}$ ) dengan kedalaman air $6 \mathrm{~cm}$. Padat tebar Tubifex sp. sebesar $150 \mathrm{~g} / \mathrm{m}^{3}$ dengan rerata berat 0,0062 $\pm 0,00032$ g. Data dianalisis menggunakan sidik ragam dan uji lanjut Duncan's Multiple Range Test. Perbedaan ketebalan media budidaya berpengaruh nyata $(P<0,05)$ terhadap produksi biomassa cacing sutera. Biomassa cacing sutera tertinggi sebesar $1745,14 \pm 143,77 \mathrm{~g} / \mathrm{m}^{3}$ atau meningkat sebesar 12,65 kali lipat dan populasi sebesar $233848,46 \pm 19265,61 \mathrm{ind} . / \mathrm{m}^{3}$ pada ketebalan media $8 \mathrm{~cm}$. Hubungan perlakuan dengan produksi biomassa cacing sutera diperoleh hubungan kuadratik mengikuti persamaan $y=-31,428 x^{2}+586,47 x-743,54$. Ketebalan media yang optimal untuk menghasilkan produksi biomassa maksimal yaitu $9,1 \mathrm{~cm}$.
\end{abstract}

Kata kunci: Bahan organik, biomassa, cacing sutera, ketebalan, limbah budidaya lele

\begin{abstract}
This research aims to know the influence of thickness of culture medium using waste sludge of catfish cultivation on silkworm (Tubifex sp.) biomass. Tubifex sp. was cultured in waste sludge of catfish aquaculture in different thickness $\left(2,4,8\right.$ and $12 \mathrm{~cm}$ ) with a $6 \mathrm{~cm}$ of water depth. Tubifex was stocked at $150 \mathrm{~g} / \mathrm{m}^{3}$ of density with $0.0062 \pm 0.00032 \mathrm{~g}$ of average weight. Biomass and population of Tubifex sp. Obtained from each treatment were analyzed by using analysis of varians and a posthoc test (Duncan's Multiple Range Test). The result shows that the thickness of the culture medium significantly influences the Tubifex sp. biomass production $(P<0.05)$. The highest silkworm biomass $\left(1745.14 \pm 143.77 \mathrm{~g} / \mathrm{m}^{3}\right)$ and population $\left(233,848.46 \pm 19265.61 \mathrm{ind} . / \mathrm{m}^{3}\right)$ were obtained by the treatment with $8 \mathrm{~cm}$ of medium thickness. The relationship between treatment and biomass production of Tubifex sp. is quadratic with $y=-30.405 x^{2}+552.18 x-823.55$. The optimum thickness of medium that results maximum biomass production is $9.1 \mathrm{~cm}$.
\end{abstract}

Keywords: Organic matter, Tubifex sp., thickness, waste of catfish culture

\section{Pendahuluan}

Pembenihan merupakan salah satu segmen usaha budidaya ikan yang berhadapan dengan masalah tingkat kematian larva yang tinggi. Kematian larva salah satunya disebabkan oleh ketersediaan pakan yang tidak sesuai dengan kebutuhan larva, baik dari sisi kuantitas maupun kualitas. Cacing sutera (Tubifex sp.) merupakan salah satu jenis pakan alami ikan budidaya yang potensial. Keberadaan cacing sutera di alam tidaklah tersedia sepanjang tahun, khususnya pada musim penghujan. Cacing sutera yang ditangkap dari alam tidak memiliki jaminan kualitas baik, semakin banyak kandungan bahan tercemar di alam maka akan semakin banyak bahan tercemar tersebut yang terakumulasi di dalam tubuh cacing. Semakin banyak kandungan logam berat pada suatu perairan semakin tinggi pula kandungan logam berat tersebut di dalam tubuh cacing sutera (Santoso \& Hernayanti, 2004). Tangkapan cacing sutera pada musim penghujan mengalami penurunan bahkan hilang akibat arus air yang tinggi begitu juga pada saat musim kemarau banyak selokan atau parit yang kering dan tidak dapat dijumpai cacing sutera, oleh karena itu cacing sutera tangkapan dari alam mengalami pasang surut yang sangat fluktuatif. Hasil tangkapan yang fluktuatif menyebabkan mahalnya 
harga cacing sutera dan akhirnya berimbas pada harga benih ikan (Adlan, 2014).

Budidaya cacing sutera membutuhkan media dengan kandungan bahan organik tinggi. Limbah budidaya ikan banyak mengandung partikel organik dan bakteri melimpah yang berasal dari sisa-sisa pakan yang terakumulasi di dalam kolam selama pemeliharaan, khususnya dalam sistem budidaya secara intensif (Gunadi, 2012). Limbah yang dihasilkan dari proses budidaya lele memiliki kandungan partikel organik yang melimpah. Kandungan bahan organik yang tinggi ini mungkin dapat dimanfaatkan untuk produksi cacing sutera sebagai pakan alami ikan. Untuk dapat menghasilkan Optimalisasi biomassa cacing sutera dapat dilakukan dengan mengatur media dengan ketebalan yang optimal pula. Tujuan penelitian ini untuk mengetahui pengaruh limbah budidaya lele sebagai media budidaya terhadap produksi biomassa cacing sutera, serta mengetahui ketebalan limbah budidaya lele sebagai media yang dapat menghasilkan produksi cacing sutera tertinggi.

\section{Bahan dan Metode}

\section{Bahan}

Bahan-bahan yang digunakan dalam penelitian ini, yaitu cacing sutera, limbah padat (lumpur) dan cair (air buangan) budidaya lele, aquadest serta beberapa larutan dan reagen untuk analisis kualitas air.

\section{Metode \\ Penelitian dilaksanakan di Laboratorium Basah Departemen Perikanan Fakultas Pertanian Universitas Gadjah Mada selama 45 hari dimulai pada Februari sampai dengan Maret 2016. Metode yang digunakan pada penelitian ini adalah metode eksperimen. Rancangan percobaan yang digunakan yaitu Rancangan Acak Kelompok Lengkap (RAKL) yang terdiri atas empat perlakuan dengan tiga kali ulangan pada setiap perlakuan. Kedalaman air yang digunakan yaitu $6 \mathrm{~cm}$ dari atas permukaan media.}

Rancangan percobaan yang dilakukan sebagai berikut:

$$
\begin{aligned}
& \mathrm{P} 1=\text { Ketebalan media } 2 \mathrm{~cm} \\
& \mathrm{P} 2=\text { Ketebalan media } 4 \mathrm{~cm} \\
& \mathrm{P} 3=\text { Ketebalan media } 8 \mathrm{~cm} \\
& \mathrm{P} 4=\text { Ketebalan media } 12 \mathrm{~cm}
\end{aligned}
$$

\section{Persiapan}

Wadah yang digunakan berupa nampan berukuran $40 \times 30 \times 20 \mathrm{~cm}^{3}$ sebanyak 12 buah. Wadah budidaya disusun pada rak yang terbuat dari kayu disusun menjadi tiga tingkat dengan jarak antar wadah yaitu $20 \mathrm{~cm}$. Wadah yang telah disusun dilakukan uji sistem resirkulasi.
Lumpur yang digunakan diambil dari kolam budidaya lele dengan masa pemeliharaan 90 hari. Persiapan lumpur dilakukan dengan mengumpulkan dan mengambil semua lumpur kolam pada satu bak yang sama. Lumpur kemudian disaring untuk memisahkan antara lumpur dan partikel lain yang berukuran lebih besar seperti kerikil maupun hewan kelompok gastropoda. Masing- masing wadah diisi media (lumpur) limbah budidaya lele yang telah disiapkan sebelumnya dengan kedalaman berbeda sesuai perlakuan. Media direndam air selama 24 jam dengan debit $300 \mathrm{~mL} /$ menit. Wadah budidaya diletakkan di tempat yang tidak terkena sinar matahari secara langsung. Sistem budidaya bersifat semi resirkulasi yaitu air yang digunakan untuk mengaliri media akan digunakan kembali dengan bantuan pompa kapasitas $3000 \mathrm{~L}(3 \mathrm{~m}, 50 \mathrm{~W})$ dengan asumsi kandungan bahan organik yang terkandung di dalam media tidak hilang terbawa air. Penambahan air dilakukan untuk menggantikan air yang hilang karena menguap dan bocor dari wadah budidaya.

\section{Penebaran bibit}

Cacing sutera yang akan digunakan sebagai bibit dilakukan pemuasaan terlebih dahulu sebelum dilakukan penebaran yaitu dengan cara mengalirkan air selama 24 jam tanpa diberikan pakan ataupun media berupa lumpur. Cacing sutera diperoleh dari penjual di Pasar Telo Karangkajen, Kelurahan Brontokusuman, Kecamatan Mergangsan, Kota Yogyakarta yang merupakan hasil tangkapan dari alam. Bibit cacing sutera ditebar secara merata di permukanan media. Saat dilakukan penebaran, aliran air dimatikan terlebih dahulu selama 30 menit sampai cacing sutera masuk ke dalam media. Padat tebar yang digunakan yaitu $150 \mathrm{~g} / \mathrm{m}^{2}$ atau $18 \mathrm{~g} /$ wadah (Marian \& Pandian, 1984 cit Adlan, 2014). Berat rata-rata bibit cacing sutera yang ditebar yaitu $182,33 \pm 8,51 \mathrm{ind} / \mathrm{g}$.

\section{Perawatan dan pemeliharaan}

Perawatan dilakukan dengan cara membersihkan media dari kompetitor yang mengganggu pertumbuhan cacing sutera. Pembersihan media dari lumut dilakukan setiap hari karena lumut akan mengganggu aliran air dan menutup media dari sinar matahari. Pengambilan Chironomus (cacing darah) dan pengawasan sistem resirkulasi dilakukan dan dijaga setiap hari. Pemeliharaan dilakukan dengan cara memberikan limbah cair budidaya sebagai upaya dalam meningkatkan kandungan bahan organik. Limbah cair budidaya ditampung dalam bak fiberglass berukuran $80 \times 80 \times 100 \mathrm{~cm}^{3}$ yang digunakan sebagai suplai air limbah. Penambahan limbah cair budidaya dilakukan setiap dua hari dengan tujuan menggantikan air yang hilang akibat proses penguapan dan secara 
tidak langsung sebagai pensuplai pakan. Limbah cair ditambahkan dalam bak penampungan dan langsung dipompa ke seluruh wadah pemeliharaan.

\section{Pengamatan dan sampling}

Pengamatan dilakukan setiap hari dengan mengamati pertumbuhan cacing dan mengontrol hama cacing sutera seperti cacing darah yang dapat menghabiskan bahan organik yang tersedia dalam media. Pengelolaan air dilakukan untuk memastikan jalannya sistem semi resirkulasi. Sampling dilakukan setiap 15 hari dengan mengambil sampel pada tiga tempat dalam setiap wadah, yaitu inlet, tengah dan outlet. Sampling dilakukan dengan memasukkan pipa berdiameter 2,3 cm ke dalam media sampai dasar, lalu pipa diangkat dengan menutup lubang bagian atas. Media yang diperoleh terlebih dahulu disaring sambil dibilas dengan air dan cacing dipisahkan dari substrat. Cara ini dilakukan berulang-ulang hingga cacing yang diperoleh bersih dan kemudian dilakukan penimbangan (Sinaga, 2012).

\section{Pengukuran parameter biologi, fisika dan kimia}

Parameter biologi yang diukur yaitu peningkatan biomassa dan biomassa mutlak cacing sutera. Biomassa mutlak cacing sutera dihitung berdasarkan berat cacing sutera pada saat panen dikurangi dengan berat biomassa cacing sutera pada saat tebar. Perhitungan pertumbuhan mutlak berbasis berat cacing sutera menurut Effendie (2002):

$$
G=W t-W o
$$

$$
\begin{array}{r}
\text { Keterangan : } \mathrm{G}=\text { Pertumbuhan mutlak cacing sutera }(\mathrm{g}) \\
\text { Wt }=\text { Berat saat panen cacing sutera }(\mathrm{g}) \\
\text { Wo }=\text { Berat saat tebar cacing sutera }(\mathrm{g})
\end{array}
$$

Berdasarkan persamaan tersebut, dapat diperoleh pertumbuhan mutlak yang berbasis pada biomassa $\left(\mathrm{g} / \mathrm{m}^{3}\right)$ dan populasi (ind./m³) (Djumanto, komunikasi pribadi). Parameter yang diamati yaitu suhu udara, suhu air, oksigen terlarut, $\mathrm{pH}$, karbon, bahan organik total lumpur dan air. Suhu diamati setiap hari, bahan organik lumpur dan air diukur pada saat tebar dan setelah panen menggunakan metode Walkey-Black, oksigen terlarut diukur menggunakan metode Winkler dan $\mathrm{pH}$ diamati setiap 15 hari.

\section{Pemanenan}

Cacing sutera dipanen setelah 45 hari. Cara pemanenan cacing sutera dilakukan dengan menuangkan media ke dalam seser dengan meshsize 0,5 $\mathrm{mm}$ dan dilakukan pemisahan dengan mengalirkan air. Cacing sutera yang diperoleh dan masih bercampur dengan media kemudian dimasukkan ke dalam ember yang diisi air setinggi $1 \mathrm{~cm}$ agar cacing sutera naik ke permukaan media budidaya. Ember ditutup hingga bagian dalam menjadi gelap dan dibiarkan selama 6 jam. Setelah 6 jam, cacing sutera akan membuat koloni. Cacing sutera diambil menggunakan tangan, dibersihkan kemudian ditimbang.

\section{Analisis data}

Rancangan penelitian menggunakan Model Rancangan Acak Lengkap menurut Steel \& Torrie (1991) dengan persamaan sebagai berikut :

$$
Y i j=\mu+\tau i+\varepsilon i j
$$

$$
\text { Keterangan: } \begin{aligned}
\text { Yij }= & \text { Nilai pengamatan; } \mathrm{I}=1,2,3 . . \mathrm{n} \\
\mu= & \text { Nilai tengah umum } \\
\tau i= & \text { Pengaruh perlakuan ke-I = 1,2,3..n } \\
\varepsilon= & \text { Pengaruh kesalahan percobaan } \\
& \text { yang berasal dari perlakuan ke-i yang } \\
& \text { mendapat ulangan ke-j }
\end{aligned}
$$

Data dianalisis menggunakan sidik ragam dengan tingkat kepercayaan 95\% $(\alpha=0,05)$ untuk biomassa dan populasi cacing sutera. Apabila terbukti ada beda nyata maka analisis dilanjutkan dengan Duncan's Multiple Range Test untuk mengetahui perbedaan antar perlakuan. Analisis regresi polinomial kuadratik digunakan untuk mengetahui ketebalan media yang menghasilkan biomassa cacing sutera tertinggi. Data parameter fisik dan kimia lingkungan perairan dianalisis secara deskriptif dan dibandingkan dengan referensi yang telah ada.

\section{Pembahasan}

Produksi biomassa cacing sutera

Produksi biomassa cacing sutera dapat dilihat pada Tabel 1.

Tabel 1 menunjukkan bahwa cacing sutera yang dipelihara selama 45 hari mengalami peningkatan biomassa. Biomassa cacing sutera mencapai puncak pada hari ke-45 kecuali pada media dengan ketebalan $2 \mathrm{~cm}$ (P1) yang menghasilkan puncak biomassa pada hari ke-30 dan menurun pada hari ke-45. Biomassa tertinggi terdapat pada P3 yaitu berturutturut sebesar 952,49 $\pm 230,28,1447,28 \pm 375,13$ dan $1745,14 \pm 143,77 \mathrm{~g} / \mathrm{m}^{3}$.

Produksi biomassa mutlak cacing sutera selama 45 hari pemeliharaan dapat dilihat pada Tabel 2.

Tabel 2 menunjukkan bahwa produksi tertinggi dihasilkan oleh media dengan ketebalan $8 \mathrm{~cm}$ (P3) sebesar $1745,14 \pm 143,77 \mathrm{~g} / \mathrm{m}^{3}$ dan produksi terendah dihasilkan oleh media dengan ketebalan $2 \mathrm{~cm}$ (P1) sebesar $236,92 \pm 21,32 \mathrm{~g} / \mathrm{m}^{3}$. 
Tabel 1. Produksi biomassa cacing sutera $\left(\mathrm{g} / \mathrm{m}^{3}\right)$ setiap 15 hari.

\begin{tabular}{lccc}
\hline $\begin{array}{l}\text { Perlakuan } \\
\text { (Ketebalan media) }\end{array}$ & \multicolumn{3}{c}{ Biomassa cacing sutera $\left(\mathrm{g} / \mathrm{m}^{3}\right)$} \\
\cline { 2 - 4 } & $\mathrm{H}-15$ & $\mathrm{H}-30$ & $\mathrm{H}-45$ \\
\hline P1 $(2 \mathrm{~cm})$ & $165,04 \pm 197,81^{\mathrm{a}}$ & $311,88 \pm 43,33^{\mathrm{a}}$ & $236,92 \pm 21,32^{\mathrm{a}}$ \\
P2 $(4 \mathrm{~cm})$ & $367,16 \pm 227,86^{\mathrm{b}}$ & $544,40 \pm 256,31^{\mathrm{b}}$ & $752,99 \pm 389,07^{\mathrm{b}}$ \\
P3 $(8 \mathrm{~cm})$ & $952,49 \pm 230,28^{\mathrm{c}}$ & $1447,28 \pm 375,13^{\mathrm{c}}$ & $1745,14 \pm 143,77^{\mathrm{c}}$ \\
P4 $(12 \mathrm{~cm})$ & $741,55 \pm 104,85^{\mathrm{d}}$ & $1125,35 \pm 483,91^{\mathrm{d}}$ & $1395,17 \pm 176,10^{\mathrm{d}}$ \\
\hline
\end{tabular}

Keterangan : Tanda huruf yang berbeda pada kolom yang sama menunjukkan adanya beda nyata dengan tingkat kepercayaan 95\%.

Tabel 2. Produksi biomassa mutlak cacing sutera selama pemeliharaan.

\begin{tabular}{lcccc}
\hline Perlakuan & \multicolumn{3}{c}{ Biomassa cacing sutera $\left(\mathrm{g} / \mathrm{m}^{3}\right)$} & \multirow{2}{*}{ Rerata \pm sd } \\
\cline { 2 - 4 } Ketebalan media) & Ulangan 1 & Ulangan 2 & Ulangan 3 & \\
\hline P1 $(2 \mathrm{~cm})$ & 216,42 & 235,36 & 258,97 & $236,92 \pm 21,32^{\text {a }}$ \\
P2 $(4 \mathrm{~cm})$ & 332,24 & 826,96 & 1099,76 & $752,99 \pm 389,07^{\mathrm{b}}$ \\
P3 $(8 \mathrm{~cm})$ & 1625,49 & 1904,63 & 1705,30 & $1745,14 \pm 143,77^{\mathrm{c}}$ \\
P4 $(12 \mathrm{~cm})$ & 1576,01 & 1385,27 & 1224,23 & $1395,17 \pm 176,10^{\mathrm{d}}$ \\
\hline
\end{tabular}

Keterangan : Tanda huruf yang berbeda pada kolom yang sama menunjukkan adanya beda nyata dengan tingkat kepercayaan $95 \%$.

Tabel 3. Peningkatan biomassa cacing sutera $\left(\mathrm{g} / \mathrm{m}^{3}\right)$ setiap 15 hari.

\begin{tabular}{lccc}
\hline $\begin{array}{l}\text { Perlakuan } \\
\text { (Ketebalan media) }\end{array}$ & \multicolumn{3}{c}{ Peningkatan biomassa cacing sutera $\left(\mathrm{g} / \mathrm{m}^{3}\right)$} \\
\cline { 2 - 4 } P1 $(2 \mathrm{~cm})$ & $\mathrm{H}-15$ & $\mathrm{H}-30$ & $\mathrm{H}-45$ \\
P2 $(4 \mathrm{~cm})$ & 15,04 & 146,84 & $-749,96$ \\
P3 $(8 \mathrm{~cm})$ & 217,16 & 177,24 & 208,59 \\
P4 $(12 \mathrm{~cm})$ & 802,16 & 494,79 & 297,86 \\
\hline
\end{tabular}

Tabel 4. Berat cacing sutera $(\mathrm{g})$ setiap 15 hari.

\begin{tabular}{lccc}
\hline $\begin{array}{l}\text { Perlakuan } \\
\text { (Ketebalan media) }\end{array}$ & \multicolumn{3}{c}{ Berat cacing sutera $(\mathrm{g})$} \\
\cline { 2 - 4 } & $\mathrm{H}-15$ & $\mathrm{H}-30$ & $\mathrm{H}-45$ \\
\hline P1 $(2 \mathrm{~cm})$ & 0,00617 & 0,00758 & 0,00571 \\
P2 $(4 \mathrm{~cm})$ & 0,00649 & 0,00658 & 0,00709 \\
P3 $(8 \mathrm{~cm})$ & 0,00633 & 0,00694 & 0,00746 \\
P4 $(12 \mathrm{~cm})$ & 0,00595 & 0,00654 & 0,00769 \\
\hline
\end{tabular}

Tabel 5. Populasi cacing sutera (ind. $/ \mathrm{m}^{3}$ ) setiap 15 hari.

\begin{tabular}{lccc}
\hline Perlakuan & \multicolumn{3}{c}{ Populasi cacing sutera (ind./m ${ }^{3}$ ) } \\
\cline { 2 - 4 } (Ketebalan media) & $\mathrm{H}-15$ & $\mathrm{H}-30$ & $\mathrm{H}-45$ \\
\hline P1 $(2 \mathrm{~cm})$ & $26735,89 \pm 32045,50^{\mathrm{a}}$ & $41167,78 \pm 5718,92^{\mathrm{a}}$ & $41460,13 \pm 3730,40^{\mathrm{a}}$ \\
P2 $(4 \mathrm{~cm})$ & $56542,52 \pm 35090,06^{\mathrm{b}}$ & $82748,15 \pm 38959,29^{\mathrm{b}}$ & $106171,12 \pm 54858,93^{\mathrm{b}}$ \\
P3 $(8 \mathrm{~cm})$ & $150494,20 \pm 36383,56^{\mathrm{d}}$ & $208408,30 \pm 54018,23^{\mathrm{d}}$ & $233848,46 \pm 19265,61^{\mathrm{d}}$ \\
P4 $(12 \mathrm{~cm})$ & $124580,70 \pm 17615,08^{\mathrm{c}}$ & $172178,53 \pm 74037,71^{\mathrm{c}}$ & $181371,67 \pm 22892,85^{\mathrm{c}}$ \\
\hline
\end{tabular}

Keterangan : Tanda huruf yang berbeda pada kolom yang sama menunjukkan adanya beda nyata dengan tingkat kepercayaan 95\%. 
Tabel 6. Peningkatan populasi cacing sutera (ind. $/ \mathrm{m}^{3}$ ) setiap 15 hari.

\begin{tabular}{lccc}
\hline Perlakuan & \multicolumn{3}{c}{ Peningkatan populasi cacing sutera (ind. $/ \mathrm{m}^{3}$ ) } \\
\cline { 2 - 4 } Ketebalan media) & $\mathrm{H}-15$ & $\mathrm{H}-30$ & $\mathrm{H}-45$ \\
\hline P1 $(2 \mathrm{~cm})$ & 2453,89 & 14431,89 & 292,35 \\
P2 $(4 \mathrm{~cm})$ & 32242,52 & 26205,63 & 23422,97 \\
P3 $(8 \mathrm{~cm})$ & 126194,20 & 57914,10 & 25440,16 \\
P4 $(12 \mathrm{~cm})$ & 100280,70 & 47597,83 & 9193,14 \\
\hline
\end{tabular}

Peningkatan biomassa cacing sutera dapat dilihat pada Tabel 3.

Tabel 3 menunjukkan bahwa peningkatan biomassa tertinggi pada setiap sampling dan panen terdapat pada media dengan ketebalan $8 \mathrm{~cm}$ (P3). Peningkatan tertinggi terjadi pada awal pemeliharaan yaitu mencapai $802,16 \mathrm{~g} / \mathrm{m}^{3}$ dan menurun pada saat panen menjadi $297,86 \mathrm{~g} / \mathrm{m}^{3}$. Media dengan ketebalan $2 \mathrm{~cm}$ (P1) mengalami penyusutan biomassa pada saat panen. Pola peningkatan biomassa sama di setiap perlakuan yaitu mengalami puncak peningkatan di awal sampling dan menurun menuju panen.

Hasil pengamatan peningkatan berat cacing sutera dapat dilihat pada Tabel 4.

Berat cacing sutera setiap 15 hari mengalami peningkatan di setiap pengamatan kecuali pada media dengan ketebalan $2 \mathrm{~cm}$ yang mengalami penyusutan berat pada saat panen. Rerata berat cacing sutera pada saat tebar sebesar $0,0062 \pm 0,00032 \mathrm{~g}$, peningkatan berat individu menunjukkan bahwa cacing sutera mengalami pertumbuhan. Media dengan ketebalan $12 \mathrm{~cm}$ pada saat panen menghasilkan berat cacing sutera paling tinggi yaitu $0,00769 \mathrm{~g}$ dan pada media dengan ketebalan $2 \mathrm{~cm}$ mengalami penurunan berat cacing sutera dengan hasil akhir sebesar $0,00571 \mathrm{~g}$. Berdasarkan hasil pengamatan berat cacing sutera setiap 15 hari, media dengan ketebalan $12 \mathrm{~cm}$ (P4) menghasilkan cacing sutera dengan bobot individu paling besar dan diikuti dengan ketebalan media 8 cm (P3).

Produksi populasi cacing sutera

Hasil pengamatan produksi populasi cacing sutera dapat dilihat pada Tabel 5.

Populasi cacing sutera diperoleh dari kepadatan cacing sutera setiap volume media. Cacing sutera dari awal pemeliharaan sampai dengan panen mengalami peningkatan populasi. Populasi tertinggi pada setiap sampling sampai dengan panen terdapat pada ketebalan media $8 \mathrm{~cm}$ (P3). Puncak populasi terdapat pada saat panen sebesar 233848,46 $\pm 19265,61$ ind. $/ \mathrm{m}^{3}$. Populasi paling rendah pada saat panen dihasilkan oleh media dengan ketebalan $2 \mathrm{~cm}$ (P1) yaitu sebesar $41460,13 \pm 3730,40 \mathrm{ind} . / \mathrm{m}^{3}$. Media dengan ketebalan $2 \mathrm{~cm}$ menghasilkan populasi cacing sutera terendah baik dari sampling sampai dengan panen.

Peningkatan populasi cacing sutera secara detail dapat dilihat pada Tabel 6 .

Peningkatan tertinggi terjadi pada hari ke-15 yaitu media dengan ketebalan $8 \mathrm{~cm}$ (P3) mencapai 126194,20 ind./m. Peningkatan populasi terendah dihasilkan oleh media dengan kedalaman $2 \mathrm{~cm}$ (P1) yaitu sebesar 292,35 ind. $/ \mathrm{m}^{3}$.

Grafik hubungan ketebalan media terhadap produksi biomassa cacing sutera dapat dilihat pada Gambar 1.

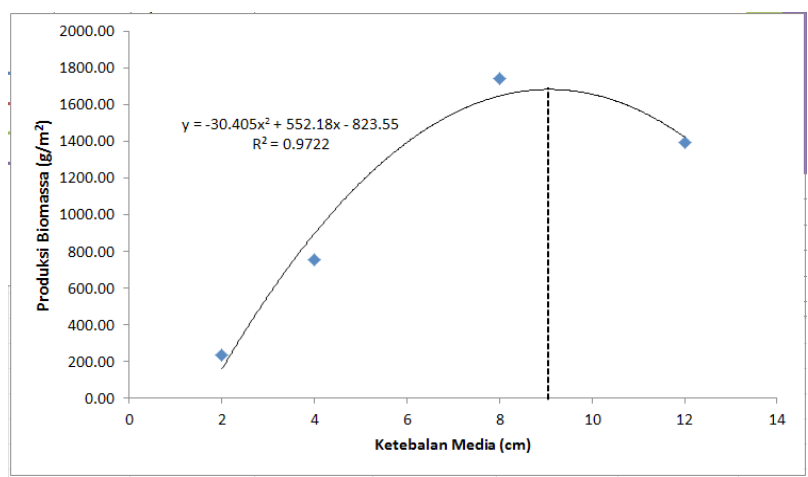

Gambar 1. Grafik hubungan ketebalan media terhadap produksi biomassa.

Grafik hubungan perlakuan (ketebalan media) terhadap produksi biomassa cacing sutera mengikuti pola kuadratik dengan persamaan $y=-30,405 x^{2}+$ $552,18 x-823,55$, untuk $x$ adalah ketebalan media dengan nilai koefisien determinasi $\left(R^{2}\right)$ sebesar 0,9722 . Peningkatan ketebalan media akan diikuti dengan peningkatan produksi biomassa cacing sutera sampai dengan ketebalan tertentu dan produksi biomassa akan menurun ketika ketebalan media ditingkatkan. Berdasarkan persamaan grafik pada Gambar 1 diperoleh ketebalan media yang optimal untuk menghasilkan biomassa cacing sutera tertinggi yaitu pada ketebalan media $9,1 \mathrm{~cm}$ dengan produksi biomassa cacing sutera sebesar 1683,45 g/m³. 


\section{Parameter fisik dan kimia}

Hasil pengamatan kandungan oksigen terlarut dan $\mathrm{pH}$ selama 45 hari pemeliharaan dapat dilihat pada Tabel 7.

Oksigen terlarut selama pemeliharaan mengalami penurunan sampai dengan panen. Oksigen terendah dihasilkan pada pengamatan di hari ke-30 yaitu $4,86 \mathrm{mg} / \mathrm{L}$ dan meningkat pada saat panen menjadi $5,6 \mathrm{mg} / \mathrm{L}$. Kandungan oksigen terlarut selama pemeliharaan masih berada pada kisaran normal. Kondisi pH selama pemeliharaan berada pada kisaran normal untuk habitat cacing sutera.
Hasil pengamatan kandungan bahan organik total pada saat tebar dan panen dapat dilihat pada Tabel 8 .

Tabel 8 menunjukkan bahwa nilai bahan organik lumpur dan air mengalami penurunan pada saat panen. Media dengan ketebalan $12 \mathrm{~cm}$ (P4) ulangan satu menunjukkan hasil yang berbeda yaitu pada awal pemeliharaan sebesar $3,49 \pm 0,30 \%$ mengalami peningkatan pada saat panen menjadi $3,91 \%$. Perlakuan ke-4 ulangan satu dan tiga, kandungan karbon pada lumpur juga mengalami peningkatan dari $2,02 \%$ menjadi $2,27 \%$ dan $2,16 \%$.

Tabel 7. Kandungan oksigen terlarut dan $\mathrm{pH}$ air.

\begin{tabular}{lccccc}
\hline Parameter & Tebar & Hari ke-15 & Hari ke-30 & Hari ke-45 & $\begin{array}{c}\text { Kisaran normal } \\
\text { (Effendi, 2013) }\end{array}$ \\
\hline \multirow{2}{*}{ DO $(\mathrm{mg} / \mathrm{L})$} & 6,72 & 6,1 & 4,86 & 5,6 & $2,5-7$ \\
& 6,14 & 6,34 & 5,24 & 5,8 & \\
$\mathrm{pH}$ & 6,3 & 6,2 & 5,8 & 6,3 & $5,5-8$ \\
\hline
\end{tabular}

Tabel 8. Analisis bahan organik total pada saat tebar dan panen

\begin{tabular}{|c|c|c|c|c|c|c|c|}
\hline \multirow{2}{*}{$\begin{array}{l}\text { Perlakuan } \\
\text { (Ketebalan media) }\end{array}$} & \multirow[b]{2}{*}{ Ulangan } & \multicolumn{3}{|c|}{ Tebar } & \multicolumn{3}{|c|}{ Panen } \\
\hline & & $\begin{array}{l}\text { BO lumpur } \\
(\%)\end{array}$ & $\begin{array}{c}\text { C lumpur } \\
(\%)\end{array}$ & $\begin{array}{l}\text { BO air } \\
(\mathrm{mg} / \mathrm{L})\end{array}$ & $\begin{array}{l}\text { BO lumpur } \\
(\%)\end{array}$ & $\begin{array}{l}\text { C lumpur } \\
(\%)\end{array}$ & $\begin{array}{l}\text { BO air } \\
\text { (mg/L) }\end{array}$ \\
\hline \multirow{3}{*}{$\mathrm{P} 1(2 \mathrm{~cm})$} & 1 & \multirow{12}{*}{$3,49 \pm 0,30$} & \multirow{12}{*}{2,02} & \multirow{12}{*}{42,71} & 2,76 & 1,6 & \multirow{12}{*}{35,43} \\
\hline & 2 & & & & 2,9 & 1,68 & \\
\hline & 3 & & & & 3,16 & 1,83 & \\
\hline \multirow{3}{*}{$\mathrm{P} 2(4 \mathrm{~cm})$} & 1 & & & & 3,04 & 1,76 & \\
\hline & 2 & & & & 2,61 & 1,52 & \\
\hline & 3 & & & & 3,31 & 1,92 & \\
\hline \multirow{3}{*}{ P3 (8 cm) } & 1 & & & & 3,21 & 1,86 & \\
\hline & 2 & & & & 3,08 & 1,79 & \\
\hline & 3 & & & & 3,38 & 1,96 & \\
\hline \multirow{3}{*}{$\mathrm{P} 4(12 \mathrm{~cm})$} & 1 & & & & 3,91 & 2,27 & \\
\hline & 2 & & & & 3,09 & 1,79 & \\
\hline & 3 & & & & 3,73 & 2,16 & \\
\hline
\end{tabular}

Keterangan: $\mathrm{BO}=$ Bahan organik, $\mathrm{C}=$ Karbon

Tabel 9. Pengamatan suhu minimum-maksimum selama pemeliharaan

\begin{tabular}{llllllllll}
\hline \multirow{2}{*}{ Suhu } & \multirow{2}{*}{ Kisaran } & \multirow{2}{*}{ Satuan } & \multicolumn{7}{c}{ Pengamatan minggu ke- } \\
\cline { 4 - 10 } & & & 1 & 2 & 3 & 4 & 5 & 6 & 7 \\
\hline \multirow{2}{*}{ Udara } & Minimum & ${ }^{\circ} \mathrm{C}$ & 24 & 24 & 24 & 24 & 24 & 24 & 24 \\
& Maksimum & ${ }^{\circ} \mathrm{C}$ & 32 & 32 & 32 & 32 & 32 & 32 & 32 \\
\multirow{2}{*}{ Air } & Minimum & ${ }^{\circ} \mathrm{C}$ & 27 & 27 & 28 & 27 & 27 & 27 & 27 \\
& Maksimum & ${ }^{\circ} \mathrm{C}$ & 36 & 35 & 36 & 36 & 35 & 36 & 36 \\
\hline
\end{tabular}


Hasil pengamatan suhu udara dan air selama 45 hari pemeliharaan dapat dilihat pada Tabel 9.

Suhu air mengalami fluktuasi setiap hari dibandingkan dengan suhu udara. Suhu udara minimum yaitu sebesar $24^{\circ} \mathrm{C}$ dan suhu udara maksimum sebesar $32{ }^{\circ} \mathrm{C}$, sedangkan suhu air minimum sebesar $27^{\circ} \mathrm{C}$ dan suhu air maksimum sebesar $36{ }^{\circ} \mathrm{C}$.

\section{Pembahasan}

Cacing sutera yang dipelihara selama 45 hari mengalami peningkatan biomassa dan populasi. Hasil sampling cacing sutera menunjukkan pola peningkatan yang sama pada semua perlakuan, yaitu mengalami puncak pada hari ke-45 kecuali pada ketebalan media $2 \mathrm{~cm}$ (P1). Pertumbuhan dan kelahiran individu baru pada saat puncak populasi mengakibatkan peningkatan jumlah individu dan bobot biomassa. Meningkatnya biomassa cacing sutera sampai dengan panen menunjukkan bahwa cacing sutera mampu tumbuh dengan memanfaatkan media budidaya yang kaya bahan organik (Adlan, 2014). Penurunan biomassa dan populasi disebabkan karena jumlah nutrien yang dibutuhkan oleh cacing sutera untuk tumbuh dan berkembang tidak mencukupi sehingga mengakibatkan persaingan makanan dan diikuti kematian antar individu (Bintaryanto \& Taufikurohman, 2013).

Media dengan ketebalan $2 \mathrm{~cm}$ (P1) mengalami puncak biomassa dan populasi pada hari ke-30 dan menurun pada hari ke-45. Penurunan biomassa pada ketebalan media $2 \mathrm{~cm}$ (P1) diduga karena ketersediaan bahan organik dalam media tidak mencukupi hingga waktu panen. Kandungan bahan organik pada saat tebar sebesar $3,49 \%$ dan menurun pada saat panen menjadi $2,94 \pm 0,2 \%$. Asumsi ini didasarkan karena P1 memiliki ketebalan media paling rendah dibanding dengan perlakuan lain sehingga setelah hari ke-30 cacing sutera banyak yang mati akibat terjadinya persaingan dalam memanfaatkan makanan. Berdasarkan hasil pengamatan bobot cacing sutera pada P1 mengalami penyusutan berat yaitu di hari ke-30 sebesar 0,00758 g menjadi $0,00571 \mathrm{~g}$. Kandungan bahan organik ketika panen pada ketebalan media $2 \mathrm{~cm}$ (P1) menunjukkan nilai paling rendah dibandingkan dengan perlakuan lain. Hasil pengukuran bahan organik pada saat tebar yaitu $3,49 \pm 0,30 \%$ dan menurun pada semua ulangan saat panen berturut-turut dari ulangan satu sampai tiga menjadi 2,76\%,2,9\% dan 3,16\%. Hasil tersebut membuktikan bahwa kandungan bahan organik pada ketebalan media $2 \mathrm{~cm}$ (P1) tidak dapat bertahan sampai dengan panen. Febrianti (2004) menyatakan bahwa cacing sutera mendapatkan makanan berupa bakteri dan partikel organik hasil dekomposisi bahan organik oleh bakteri. Pertumbuhan cacing sutera yang tidak diikuti dengan ketersediaan pakan yang cukup menyebabkan penurunan produksi dan penyusutan berat setiap individu. Kematian dan penyusutan berat setiap individu inilah yang menyebabkan penurunan biomassa pada media dengan ketebalan $2 \mathrm{~cm}$ (P1) setelah hari ke-30.

Produksi biomassa cacing sutera mengikuti pola persamaan kuadratik terhadap ketebalan media dengan biomassa tertinggi dihasilkan oleh media dengan ketebalan $8 \mathrm{~cm}$ (P3). Pengaruh ketebalan media terhadap biomassa cacing sutera mengikuti persamaan $y=-30,405 x^{2}+552,18 x-823,55$ untuk $x$ ketebalan media dan y biomassa cacing sutera. Nilai koefesien determinasi sebesar $\mathrm{R}^{2}=0,9722$. Persamaan ini diperoleh berdasarkan hasil produksi dari semua perlakuan. Ketebalan media yang optimal untuk menghasilkan biomassa cacing sutera maksimal yaitu $9,1 \mathrm{~cm}$.

Produksi biomassa cacing sutera meningkat seiring dengan peningkatan ketebalan media akan tetapi pada ketebalan media tertentu produksi cacing sutera akan menurun. Puncak populasi berdasarkan persamaan kuadratik dihasilkan oleh media dengan ketebalan 9,1 cm dan menghasilkan produksi biomassa cacing sutera sebesar $1683,45 \mathrm{~g} / \mathrm{m}^{3}$. Ketebalan media diduga akan berpengaruh terhadap ketersediaan kandungan oksigen di dalam media. Oksigen terlarut digunakan sebagai salah satu senyawa dalam membantu proses dekomposisi bahan organik, apabila proses dekomposisi terhambat maka kandungan bahan organik sampai batas tertentu dapat meracuni cacing sutera. Pursetyo \& Putra (2011) mengemukakan bahwa cacing golongan Oligochaeta dapat memanfaatkan bahan organik secara langsung sebagai sumber nutrien bagi tubuhnya. Kandungan bahan organik dapat bernilai tinggi di awal proses dekomposisi namun secara perlahan akan mengalami penurunan seiring berlangsungnya proses dekomposisi (Boyd, 1979). Peningkatan bahan organik pada media dengan ketebalan $12 \mathrm{~cm}$ (P4) diduga disebabkan karena terhambatnya proses dekomposisi. Hal inilah yang mengakibatkan terhambatnya proses dekomposisi karena pada kedalaman tertentu kandungan oksigen terlarut dalam lumpur diduga menurun seiring dengan meningkatnya ketebalan media.

Kandungan oksigen terlarut selama pemeliharaan berada pada kisaran yang sesuai untuk pertumbuhan cacing sutera. Kandungan oksigen terlarut terendah selama pemeliharaan yaitu $4,86 \mathrm{mg} / \mathrm{L}$ pada sampling hari ke-30 dan oksigen terlarut tertinggi mencapai $6,72 \mathrm{mg} / \mathrm{L}$. Putri (2014) menyebutkan bahwa cacing sutera berkembang biak dengan baik pada media 
yang mempunyai kandungan oksigen terlarut berkisar antara 2,75-5 mg/L. Suhu optimal cacing sutera berkisar antara $25-28{ }^{\circ} \mathrm{C}$. Suhu air selama pemeliharaan tidak mengalami fluktuasi besar, akan tetapi suhu yang dihasilkan selama pengamatan cukup tinggi dan jauh dari kisaran normal untuk pertumbuhan cacing sutera. Kisaran suhu air selama pemeliharaan yaitu $27-36^{\circ} \mathrm{C}$ dan suhu udara sebesar 24-32 ${ }^{\circ} \mathrm{C}$. Penggunaan bahan plastik sebagai wadah diduga menjadi penyebab kisaran suhu menjadi tinggi, selain itu ukuran wadah yang kecil juga membantu peningkatan suhu secara cepat. Asumsi ini diperkuat oleh Bintaryanto \& Taufikurohman (2013) yang menyebutkan bahwa bak plastik tidak dapat menyebarkan panas dari lingkungan ke lingkungan akan tetapi panas yang diperoleh tetap terperangkap pada wadah budidaya sehingga cacing tidak dapat berkembang biak dengan maksimal. Suhu bukan faktor pembatas bagi cacing famili Oligochaeta, namun dapat mempengaruhi sifat fisik dan kimia air serta dapat mempercepat proses biokimia. Jika suhu air meningkat maka laju metabolisme dan kebutuhan akan oksigen juga meningkat (Pennak, 1953)

Selain makanan, pertumbuhan cacing sutera dipengaruhi oleh faktor-faktor lain seperti ruang (tempat) dan lingkungan (Febrianti, 2004). Ketebalan media yang berbeda akan mengubah faktor ruang pada wadah yang sama. Ruang media akan meningkat seiring dengan meningkatnya ketebalan media. Lingkungan diduga menjadi faktor yang berpengaruh dalam penurunan produksi biomassa. Pada media dengan ketebalan lebih dari 9,1 cm akan mengakibatkan suhu media menurun dan menjadi tidak sesuai untuk pertumbuhan cacing sutera. Cacing sutera akan membenamkan diri ke dalam lumpur pada saat suhu tinggi dan ketika suhu rendah cacing sutera akan naik ke permukaan. Dengan demikian, pada ketebalan media lebih dari 9,1 cm akan mengalami penurunan produksi cacing sutera.

Menurut Efendi (2003) bahan organik perairan alami berkisar $10-30 \mathrm{mg} / \mathrm{L}$ sedangkan daerah yang mengalami penyuburan mencapai $100 \mathrm{mg} / \mathrm{L}$. Bahan organik yang tinggi dapat menurunkan kualitas suatu perairan. Bahan organik air selama pemeliharaan memiliki kisaran nilai cukup tinggi yaitu $42,71 \mathrm{mg} / \mathrm{L}$ di saat tebar dan menurun menjadi $35,43 \mathrm{mg} / \mathrm{L}$ pada saat panen. Hasil pengamatan bahan organik air selama pemeliharaan menunjukkan bahwa air yang digunakan termasuk air yang mengalami penyuburan. Penurunan kandungan bahan organik dapat terjadi akibat meningkatnya aktivitas perombakan oleh mikroorganisme (Adlan, 2014).

Hasil produksi biomassa cacing sutera pada eksperimen ini menunjukkan nilai yang relatif rendah dibandingkan dengan penelitian-penelitian sebelumnya. Hossain et al,. (2001) memproduksi cacing sutera sebesar $4000-5000 \mathrm{~g} / \mathrm{m}^{2}$ dalam 80 hari dengan media kombinasi bungkil kedelai dan mustard oil cake. Pursetyo dan Putra (2011) menghasilkan $3180,0 \pm 314,7 \mathrm{~g} / \mathrm{m}^{2}$ dengan media lumpur dan kotoran ayam kering dengan pemupukan setiap lima hari. Mollah et al. (2012) dapat menghasilkan cacing sutera sebesar $2802,6 \pm 220,3 \mathrm{~g} / \mathrm{m}^{2}$ pada media pasir halus, kotoran sapi, mustard oil cakedan wheat bran. Rendahnya produksi biomassa cacing sutera ini disebabkan karena perbedaan penggunaan bahan sebagai media. Pada penelitian ini, limbah digunakan sebagai media yang dianggap sebagai sesuatu yang tidak menguntungkan. Penelitian ini menghasilkan produksi yang lebih tinggi dibanding dengan penelitian Findy (2011). Penelitiaan tersebut menghasilkan biomassa tertinggi pada saat panen yaitu sebesar 1346,36 $\pm 139,64 \mathrm{~g} / \mathrm{m}^{2}$. Adlan (2014) menghasilkan produksi biomassa cacing sutera sebesar 1933,71 $\pm 156,95 \mathrm{~g} / \mathrm{m}^{2}$, walaupun tidak beda nyata karena menghasilkan produksi biomassa yang sama berdasarkan tebar yaitu 12,64 kali lipat.

Rendahnya produksi biomassa cacing sutera diduga juga disebabkan oleh larva Chironomus (cacing darah). Organisme ini merupakan kompetitor makanan bagi cacing sutera. Chironomus adalah serangga semacam nyamuk (Febrianti, 2004). Chironomus ditemukan pada awal pemeliharaan sampai pada akhir pemeliharaan, sehingga organisme ini diduga menjadi salah satu penyebab rendahnya produksi biomassa cacing sutera. Chironomus memanfaatkan bahan organik sebagai sumber makanan, Chironomus biasanya membangun rumah menyerupai goa yang tampak berlubang-lubang di permukaan lumpur (Bachtiar, 2008). Organisme ini tidak dapat dihindari karena media budidaya diletakkan pada tempat terbuka. Keberadaan Chironomus selama pemeliharaan diminimalisasi dengan cara mengambilnya setiap hari.

Pertumbuhan cacing sutera yang tidak merata di setiap perlakuan menjadi penyebab utama tingginya nilai deviasi. Bagian inlet menghasilkan biomassa dan populasi paling rendah dibanding dengan yang lain, hal ini diduga karena pada bagian inlet air masuk langsung menuju wadah yang berasal dari wadah sebelumnya yang berada $20 \mathrm{~cm}$ di atas media sehingga air yang masuk menimbulkan gelombang dan cacing sutera tidak banyak yang tumbuh pada bagian tersebut.

\section{Kesimpulan dan Saran}

Kesimpulan

Produksi biomassa cacing sutera akan meningkat 
seiring dengan peningkatan ketebalan media sampai dengan titik tertentu dan produksi cacing sutera akan menurun setelah mencapai ketebalan optimal. Produksi biomassa cacing sutera mengikuti perasamaan $y=-30,405 x^{2}+552,18 x-823,55$ Ketebalan media yang optimal dalam memproduksi biomassa cacing sutera yaitu 9,1 cm dan menghasilkan biomassa sebesar $1683,45 \mathrm{~g} / \mathrm{m}^{3}$.

\section{Saran}

Penelitian mengenai cacing sutera di setiap kolom media perlu dilakukan untuk mengetahui persebaran pertumbuhan cacing sutera di setiap kolom media. Pemberian pakan susulan disarankan dilakukan untuk menjaga dan meningkatkan ketersediaan pakan pada media, sehingga cacing sutera dapat berkembangbiak dengan baik mengikuti peningkatan biomassa dan populasi.

\section{Daftar Pustaka}

Adlan, M.A. 2014. Pertumbuhan biomassa cacing sutera (Tubifex sp.) pada media kombinasi pupuk kotoran ayam dan ampas tahu. Departemen Perikanan Fakultas Pertanian, Universitas Gadjah Mada. Yogyakarta.

Bachtiar, Y. 2008. Menghasilkan Pakan Untuk Ikan Hias. Agromedia Pustaka. Jakarta.

Bintaryanto, B.W \& Taufikurohmah. 2013. Pemanfaatan campuran limbah padat (Sludge) pabrik kertas dan kompos sebagai media budidaya cacing sutera (Tubifex sp.). UNESA J. of Chemistry 2.

Efendi, H. 2003. Telaah Kualitas Air Bagi Pengelolaan Sumber Daya dan Lingkungan Air. Kanisius. Yogyakarta.

Effendi, M. 2013. Beternak Cacing Sutera Cara Modern. Penebar Swadaya. Jakarta.

Effendie, M.I. 2002. Biologi Perikanan. Yayasan Pustaka Nusatama. Yogyakarta.

Febrianti, D. 2004. Pengaruh pemupukan harian dengan kotoran ayam terhadap pertumbuhan populasi dan biomassa cacing sutera (Limnodrilus). Fakultas Perikanan dan IImu Kelautan Institut Pertanian Bogor. Bogor.

Findy, S. 2011. Pengaruh tingkat pemberian kotoran sapi terhadap pertumbuhan biomassa cacing sutera (Tubificidae). Institut Pertanian Bogor. Bogor.
Gunadi, B. 2012. Minimalisasi limbah nitrogen dalam budidaya ikan lele (Clarias gariepinus) dengan sistem akuakultur berbasis jenjang rantai makanan. Fakultas Perikanan dan Kelautan IPB. Bogor.

Hossain, A., M. Hasan \& M. F. A. Mollah. 2001. Effect of soybean meal and mustard oil cake on the production of fish live food tubificid worm in bangladesh. World J. of Fish and Marine Science 3: 183-189.

Mollah, M.F.A., K. Mosharaf \& Mariom. 2012. Selection of suitable media and intervals of media inoculation for culturing tubificid worms. J. Bangladesh Agril. Univ. 10:325-330.

Pennak, R.W. 1978. Freshwater Invertebrate of The United States. $2^{\text {nd }}$ Ed. A Wiley Intescience Publication. John Willey and Sons. New York.

Pursetyo, A\& E. Putra. 2011. Produksi pupuk organik kascing (bekas cacing) dari limbah peternakan dan limbah pasar berbantuan cacing Lumbricus rubellus. Jurusan Teknik Kimia. Fakultas Teknik. Universitas Dipenogoro. Semarang.

Putri, D.S. 2014. Pemanfaatan media kotoran ayam dan limbah ikan lele pada budidaya cacing sutra (Tubificidae) dengan sistem resirkulasi wadah bertingkat. Sekolah Pasca Sarjana Institut Pertanian Bogor. Bogor. 34

Santoso, S \& Hernayanti. 2004. Cacing sutera sebagai bio monitor pencemaran logam berat kadmium dan seng dalam leachate tpa sampah gunung tugel purwokerto. Program Studi Biologi. Institut Teknik Surabaya. Surabaya.

Shafrudin. D., D. Efiyanti \& Widanarni. 2005. Pemanfaatan ulang limbah organik dari substrak Tubifex sp. di alam. J. Akuakultur Indonesia 4 (2): 97-102.

Sinaga, T. 2012. Keanekaragaman makrozoobentos sebagai indikator kualitas perairan danau toba balige kabupaten toba samosir. Universitas Sumatra Utara. 93

Steel, R.G.D \& Torrie. J.H. 1991. Principles and Procedures of Statistics (Prinsip dan Prosedur Statistika, alih bahasa: Bambang Sumantri). $2^{\text {nd }}$ Ed. Gramedia Pustaka Utama. Jakarta. 